Proceedings of the International Conference on Oxide Materials for Electronic Engineering, May 29-June 2, 2017, Lviv

\title{
Structure, Optical and Electric Properties of Opal-Bismuth Silicate Nanocomposites
}

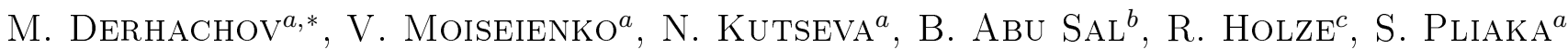 \\ AND A. YEVCHYK ${ }^{a}$ \\ ${ }^{a}$ Oles Honchar Dnipro National University, Gagarina 72, 49010 Dnipro, Ukraine \\ ${ }^{b}$ Applied Physics Department, Tafila Technical University, P.O. Box 40, Al-Eis 66141, Tafila, Jordan \\ ${ }^{c}$ Technische Universität Chemnitz, Institute of Chemistry, Str. der Nationen 62, D-09111 Chemnitz, Germany
}

Synthetic opals composed of $300 \mathrm{~nm}$ silica spheres are impregnated with a $\mathrm{Bi}_{12} \mathrm{SiO}_{20}$ melt at $1190 \mathrm{~K}$. Structure and properties of the as-prepared samples are studied by employing the scanning electron microscopy, X-ray diffraction, and optical spectroscopy and direct current conductivity techniques. The nanocomposites are found to be multi-phase systems composed of $\mathrm{Bi}_{12} \mathrm{SiO}_{20}, \mathrm{Bi}_{4} \mathrm{Si}_{3} \mathrm{O}_{12}$ and $\mathrm{SiO}_{2}$ crystallites with an average linear size not less than $20 \mathrm{~nm}$. Formation of $\mathrm{Bi}_{4} \mathrm{Si}_{3} \mathrm{O}_{12}$ crystallites becomes possible as a result of changing in the $\mathrm{Bi}_{2} \mathrm{O}_{3}-\mathrm{SiO}_{2}$ molar ratio due to the melting of silica spheres. The Raman intensity redistribution observed by surface scanning may be caused by both composition inhomogeneity and concentration of the exciting radiation field at composite defects. The "red" shift of photoluminescence band is observed. Activation energy of direct current conductivity is estimated as $1.1 \mathrm{eV}$.

DOI: $10.12693 /$ APhysPolA.133.847

PACS/topics: 81.07.Bc, 81.40.Tv, 81.70.Fy, 78.67.Bf

\section{Introduction}

Opal matrix nanocomposites on the base of colloidal crystal templates filled with various active components, providing an effective interaction with electromagnetic field, are very promising materials for applications in photonics, light beam-operating and energy storage systems $[1,2]$. Their properties are determined by both properties of the embedded components and composite topology. The composites may also serve as model objects for investigating crystallization and charge transfer phenomena under restricted volume conditions [3, 4].

Among the majority of active dielectric materials that can be embedded into opal pores the bismuth silicate $\left(\mathrm{Bi}_{12} \mathrm{SiO}_{20}\right)$ crystal (space group I23) was chosen as that has the prominent photorefractive, piezo- and electrooptic properties. All of this allows us to expect a wide application of the nanocomposite in applied and photorefractive optics. The previous characterization of opals impregnated with the bismuth silicate melt was performed by the review Raman spectra measurements in earlier paper [5].

The aim was to determine the obtained composite structure depending on the preparation conditions and to investigate the composite optical and electric properties, especially the Raman and photoluminescence spectra with using optical microscopy technique.

${ }^{*}$ corresponding author; e-mail: derhachov.mp@gmail.com

\section{Experimental}

Bare opals were grown by natural sedimentation of monodisperse silica spheres that were synthesized by the Stöber technique [6]. The precipitates were dried in air and then were sequentially annealed at $400 \mathrm{~K}$ and $1120 \mathrm{~K}$ for several hours. Finally, the opals were as plates of about $5 \mathrm{~mm} \times 8 \mathrm{~mm}$ in size and up to $2 \mathrm{~mm}$ thick.

Silica spheres in the opals were arranged in hexagonally close-packed layers, perpendicular to the growth direction. An average sphere diameter derived from the growth surface images obtained by X-ray microanalyzer JEOL JXA 8200 (Institute of Physics of NAS of Ukraine) and the Bragg light reflection spectra, as described in the paper [5], was $306 \pm 15 \mathrm{~nm}$. Average linear sizes of channels, tetrahedral and octahedral pores, calculated accordingly to the relations in the paper [7], were 46,70 , and $120 \mathrm{~nm}$, respectively.

The composites were obtained by impregnating opals with the bismuth silicate melt by action of capillary forces. Bare opal samples placed in air-resistance furnace were contacted with the melt at $1190 \mathrm{~K}$ during time interval from 5 to $15 \mathrm{~min}$. The temperature was higher than the $\mathrm{Bi}_{12} \mathrm{SiO}_{20}$ congruent melting one, $1173 \mathrm{~K}$. After contacting with the melt, the samples were cooled down, cleaned, and polished mechanically. The thickness of sample plates for electric measurements was $1.0 \mathrm{~mm}$. The growth opal plane and the opposite one were covered with the $0.25 \mathrm{~cm}^{2}$ platinum electrodes by using thermal vacuum deposition.

Structural investigations of the composites were made by employing scanning electron microscope (SEM) Nova NanoSEM and X-ray diffractometer DRON-2.0 $\left(\mathrm{Cu} K_{\alpha}\right.$ radiation). X-ray diffraction (XRD) patterns for the untreated and polished growth opal surfaces were obtained. 
Non-polarized Raman and photoluminescence spectra were measured at room temperature. The used techniques were two confocal Raman microscopes (LabRam HR800 with a 50xLWD lens and UV-Visible-NIR Olympus BX41 with a triple spectrometer Horiba Jobin-Yvon T64000), both equipped with a $514.5 \mathrm{~nm}$ Ar-Kr laser and a liquid nitrogen-cooled CCD detector, and spectrometer based on a DFS-12 double monochromator with a photon counting system, equipped with a $532 \mathrm{~nm}$ or $407 \mathrm{~nm}$ excitation laser. The laser beam spot size on the composite surface was varied from $1 \mathrm{~mm}$ to $500 \mathrm{~nm}$; its value was determined by the scanning edge method. An incident radiation was normal to the growth opal surface, in all cases.

Direct current conductivity was measured with using a current amplifier U5-11 by standard technique within a 290-670 K temperature range. The heating and cooling rates were the same and not more than $2 \mathrm{~K}$ per min. Previous dielectric measurements at the frequency of $1 \mathrm{kHz}$ were performed by using the bridge method at room temperature.

\section{Results and discussion}

SEM image of the composite untreated surface is shown in Fig. 1. The image demonstrates an existence of porous structure of the obtained nanocomposite with inclusions of crystalline grains with linear sizes more than $20 \mathrm{~nm}$.

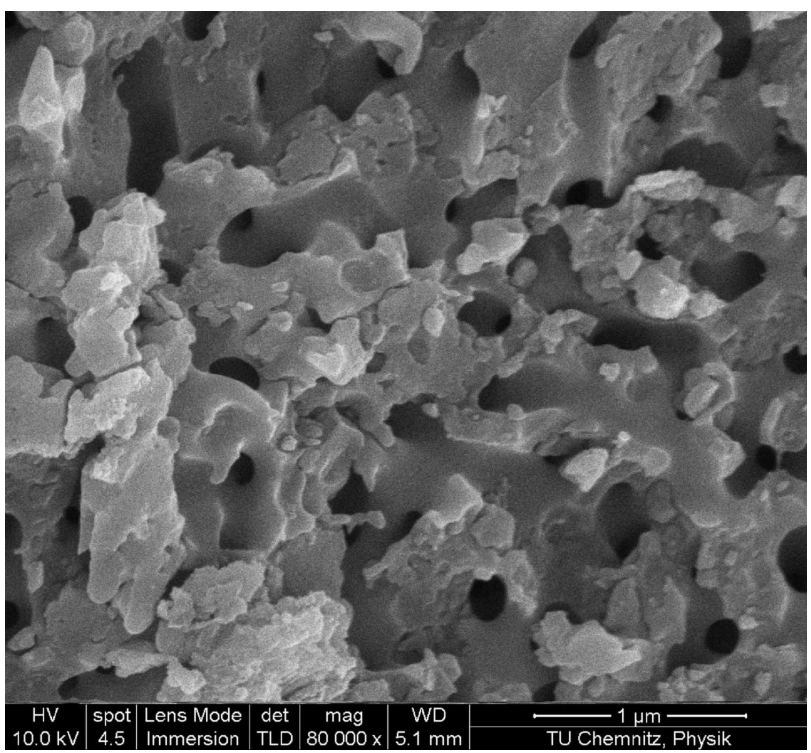

Fig. 1. SEM image of the composite untreated surface.

The results of the XRD measurements for bare opal and composites with different time durations of melt contact (corrected for background) both with XRD patterns of the bismuth silicate powder and the bismuth orthosilicate $\left(\mathrm{Bi}_{4} \mathrm{Si}_{3} \mathrm{O}_{12}\right)$ reference data [8] are presented in Fig. 2. The broad diffusive halo in the XRD pat- tern of bare opal (curve 1 in Fig. 2) testifies its amorphous state with a size of coherently diffracting domains of about $3 \mathrm{~nm}$. This value is correspondent to the diameter of silica nuclei that appear at the first stage of sphere growth as a result of the polymerization of silicon acid monomers [7]. As can be seen from comparison of XRD patterns 1, 2 and 4 presented in Fig. 2, the composite obtained under shorter time interval is a mixture of amorphous opal state and crystalline state that is close to $\mathrm{Bi}_{12} \mathrm{SiO}_{20}$ phase, but it is not exactly one. Finally, after keeping the sample at $1190 \mathrm{~K}$ for the longest time interval, the peaks related to the $\mathrm{Bi}_{4} \mathrm{Si}_{3} \mathrm{O}_{12}$ crystalline phase are clearly detected, together with very weak peaks of the $\mathrm{Bi}_{12} \mathrm{SiO}_{20}$ phase (curve 3 in Fig. 2) and several peaks that can be assigned to crystalline phase of $\mathrm{SiO}_{2}$. The latter ones, placed at $2 \theta=21.95^{\circ}, 36.20^{\circ}$, and $46.95^{\circ}$, are rather related to cristobalite phase with $P 4_{1} 2_{1} 2$ space group $([9,10]$ and refs. therein). The relative content of the crystalline phases can be estimated from the ratio of calculated and observed XRD intensities of corresponding lines. Thus, the approximate relationship between the bismuth orthosilicate $\left(\mathrm{Bi}_{4} \mathrm{Si}_{3} \mathrm{O}_{12}\right)$, the bismuth silicate $\left(\mathrm{Bi}_{12} \mathrm{SiO}_{20}\right)$ and the silica dioxide $\left(\mathrm{SiO}_{2}\right)$ crystalline phases is 1:0.30:0.14.

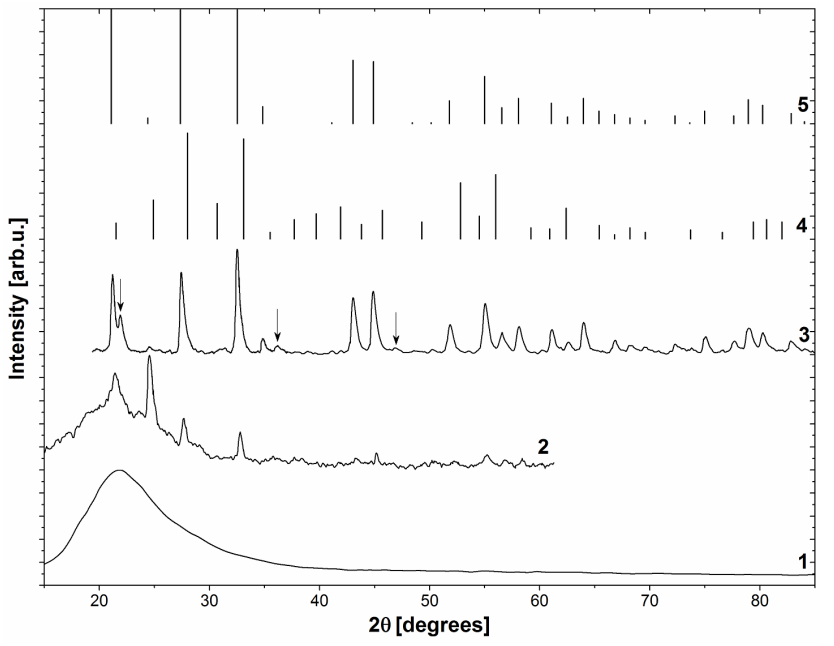

Fig. 2. X-ray diffraction patterns of the bare opal (1), the composites held at $1190 \mathrm{~K}$ for $5 \mathrm{~min}(2)$ and $15 \mathrm{~min}$ (3), the polycrystalline powders of $\mathrm{Bi}_{12} \mathrm{SiO}_{20}$ (4) and $\mathrm{Bi}_{4} \mathrm{Si}_{3} \mathrm{O}_{12}$ (5). The latter one is built on the reference data [8]. Arrows above the curve 3 show the $\mathrm{SiO}_{2}$ crystalline phase lines.

Crystallite size estimated from the full-width highmaximum (FWHM) values with using the Scherrer equation is about of $20 \mathrm{~nm}$. An analysis of the FWHM angular dependence demonstrates that the crystallite size effect plays more dominant role in broadening peaks compared with the inner stress factor.

The Raman spectrum of the opal-bismuth silicate composite was previously investigated in the earlier paper [5], and an appearance of new Raman bands was 
explained by nanosized effects and local surface modes. The present Raman measurements prove formation of the bismuth orthosilicate crystalline phase in the as-prepared composite (Fig. 3). Only several Raman bands, over a $650-770 \mathrm{~cm}^{-1}$ spectral range, cannot be related to vibrations in the bismuth silicate or bismuth orthosilicate structures. Accordingly to the XRD data discussed above, they may be assigned to the vibrations of $\left[\mathrm{SiO}_{4}\right]$ tetrahedrons in $\mathrm{SiO}_{2}$ crystallites. Small intensities of these bands are in agreement with the approximate relationship between the crystalline phases.

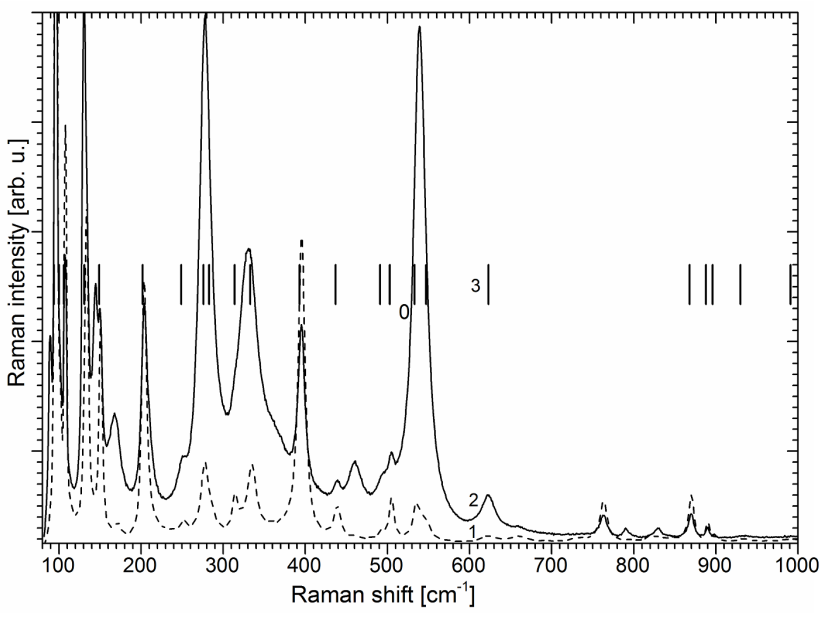

Fig. 3. Micro-Raman spectra recorded under excitation of two different volumes of the composite, held at $1190 \mathrm{~K}$ for $15 \mathrm{~min}(1,2)$. Bars (3) are correspondent to positions of the Raman bands in the reference $\mathrm{Bi}_{4} \mathrm{Si}_{3} \mathrm{O}_{12}$ spectrum at room temperature [11].

In order to explain the formation of $\mathrm{Bi}_{4} \mathrm{Si}_{3} \mathrm{O}_{12}$ crystalline phase one should be taken into account that there are two stable crystalline states in the $\mathrm{Bi}_{2} \mathrm{O}_{3}-\mathrm{SiO}_{2}$ phase diagram. One of them, the bismuth silicate phase, is correspondent to a $6: 1$ molar ration, and the other is the bismuth orthosilicate $\mathrm{Bi}_{4} \mathrm{Si}_{3} \mathrm{O}_{12}$ phase that can be obtained from the melt at a 2:3 molar ratio. At the beginning of impregnation procedure, a molar ratio is $6: 1$. In order to satisfy the change in molar ratio, the melting of silica spheres should be assumed. According to the shell-like model [7], the silica sphere with a $306 \mathrm{~nm}$ diameter consists of spherical core of about $100 \mathrm{~nm}$ surrounded by the $30-40 \mathrm{~nm}$ spherical silica particles. This structure is porous, of course, and has a rough surface. Its regular spherical form is caused by involving the smallest 5-7 nm silica particles in its structure. The melting temperature of these particles can be reached, in our case, accordingly to the size effect of the melting temperature for nanoscaled particles. Really, the estimated thickness of the silica surface layer needed to be melted in order to provide the proper 2:3 molar ratio is no more than $20 \mathrm{~nm}$. It is in a good agreement with the data obtained above. In case of the existence of $\mathrm{Si}-\mathrm{O}$ bonds in the embedding compound structure, the melt-globule interface could be served as an effective seed for formation of new structure along the whole pore volume.

Comparison of curves 1 and 2 in Fig. 3 testifies the Raman intensity variations in the composite spectrum. It may be explained by the change in composition throughout the sample and the concentration and inhomogeneous distribution of the exciting radiation field inside the sample volume. In addition, the light can be concentrated inside macroscopic surface and bulk structural defects filled by high-refractive component $\mathrm{Bi}_{12} \mathrm{SiO}_{20}$ or $\mathrm{Bi}_{4} \mathrm{Si}_{3} \mathrm{O}_{12}$ due to the internal reflection.

The obtained active matrix nanocomposites may be involved in the process of the optical radiation conversion, especially for application in modern solar cells, owing to such famous optical phenomena as photoluminescence and spontaneous parametric down-conversion. The composite photoluminescence spectrum was investigated under laser excitation at $407 \mathrm{~nm}$ and $514 \mathrm{~nm}$, far from the fundamental absorption edge region for all components of the composite. A weak non-structured band was detected over a range of 1.9-2.5 eV in all cases (Fig. 4). This band is most probably originated from an electronhole recombination caused by structural defects of the obtained composite. Obviously, the band may be divided into several narrower bands related to the radiative transitions in $\mathrm{Bi}_{12} \mathrm{SiO}_{20}$ or $\mathrm{Bi}_{4} \mathrm{Si}_{3} \mathrm{O}_{12}$ components. Thus, the shift of the photoluminescence maximum under surface scanning may be explained by local change in relationship between the bismuth silicate and the bismuth orthosilicate phases.

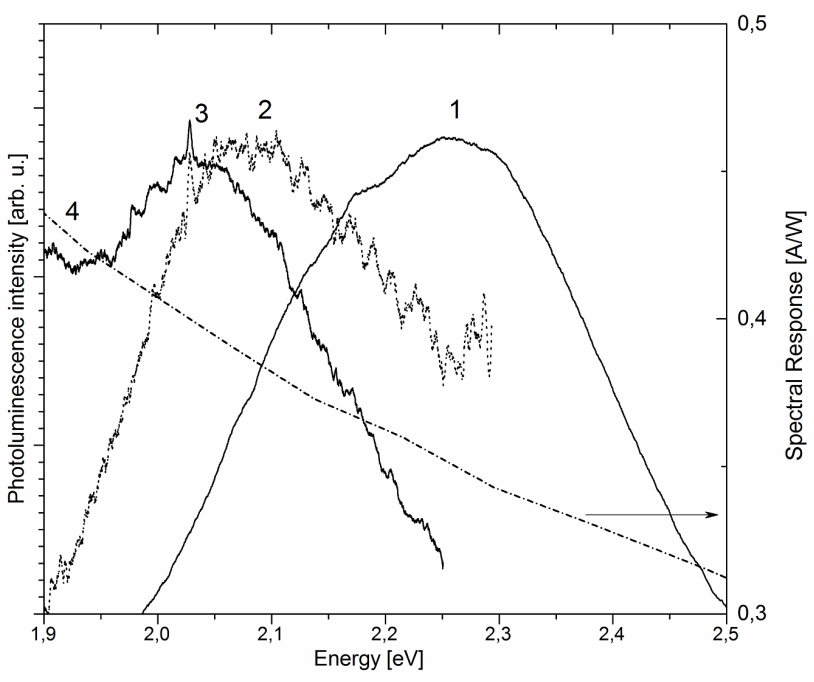

Fig. 4. The photoluminescence spectra of the composite under a $407 \mathrm{~nm}$ laser diode excitation (1) and a $514 \mathrm{~nm} \mathrm{Ar}{ }^{+}$laser excitation at two different volumes of the composite $(2,3)$ at room temperature. The curve 4 is a spectral response of typical Si solar cell.

Temperature dependences of direct-current (DC) conductivity of the obtained nanocomposite under thermocycling are shown in Fig. 5. As can be seen, the temperature behavior of DC conductivity is practically unchange- 
able both under heating and under cooling. The value of activation energy estimated from the Arrhenius plot is correlated with typical values of activation energy in bismuth orthosilicates and orthogermanates. The very low value of dielectric constant $(\varepsilon=2)$ measured at $1 \mathrm{kHz}$ at room temperature testifies the porosity of the nanocomposites.

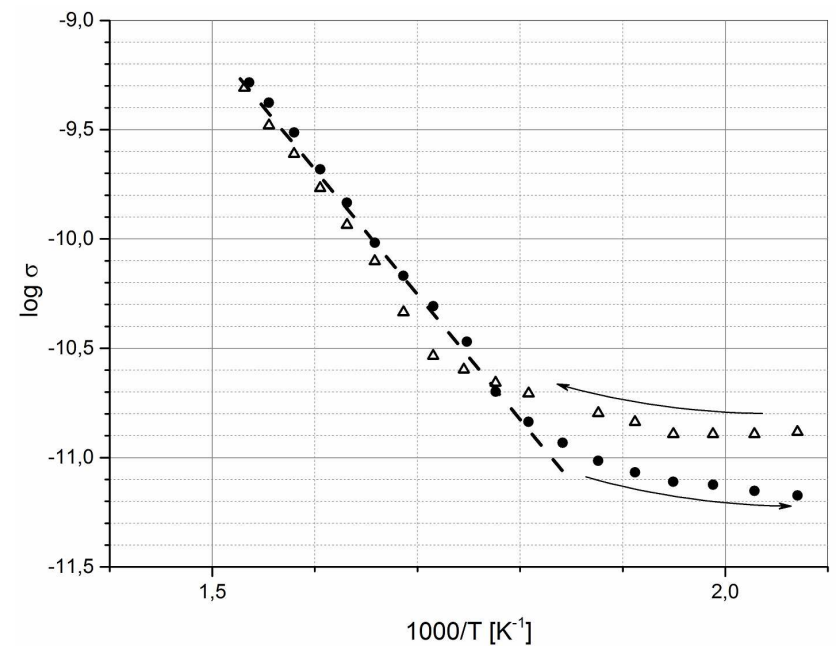

Fig. 5. Arrhenius plot of DC conductivity of the composite under heating (open triangular) and cooling (solid circles). Arrows point direct the temperature change. Dotted line is a linear approximation for estimation of the activation energy.

\section{Conclusions}

The opal-bismuth silicate nanocomposites obtained by using the melt-based technique are the mixture of several crystalline phases. These are bismuth orthosilicate $\mathrm{Bi}_{4} \mathrm{Si}_{3} \mathrm{O}_{12}$, bismuth silicate $\mathrm{Bi}_{12} \mathrm{SiO}_{20}$ and silica crystalline phase. The bismuth orthosilicate crystalline phase is dominant. Typical size of crystallites is about $20 \mathrm{~nm}$. The obtained nanocomposites are inhomogeneous and porous, with air inclusions. The formation of crystalline silica phase is most probably caused by melting of the smallest silica particles in silica spheres.

The optical properties of the composite are determined by the concentration of structural defects and, also, by the local content of both bismuth-containing phases. The relationship between these phases is defined by preparation conditions. Reasons for spectral intensity redistribution may be both the composition inhomogeneity and the structural light focusing together with concentration of the exciting radiation field nearby the surface and bulk defects.

\section{Acknowledgments}

Special thanks for Deutsche Forschungsgemeinschaft for the grant which offered one of us (B.A.) to use the Raman facilities in Technische Universität Chemnitz, Institute of Chemistry, and to Dr. Raul David Rodriguez (Institute of Physics) and to the SEM center there. We are also thankful to Dr. O. Kolomys (Institute of Semiconductor Physics of NAS of Ukraine) for luminescence measurements.

\section{References}

[1] A. Blanco, C. Lopez, Ann. Rev. Nano Res. 1, 81 (2006).

[2] E. Armstrong, C. O'Dwyer, J. Mater. Chem. C 3, 6109 (2015).

[3] B. Abu Sal, V. Moiseyenko, M. Dergachov, A. Yevchik, G. Dovbeshko, Ukr. J. Phys. Opt. 14, 119 (2013).

[4] A.E. Lukin, E.N. Ivanova, S.V. Pan'kova, V.G. Solovyev, V.L. Veisman, J. Phys. Conf. Ser. 572, 012047 (2014).

[5] V.S. Gorelik, G.I. Dovbeshko, A.V. Evchik, V.N. Moiseenko, M.P. Dergachev, Inorg. Mater. 49, 802 (2013).

[6] W. Stöber, A. Fink, E. Bohn, J. Coll. Interface Sci. 26, 62 (1968).

[7] V.M. Masalov, N.S. Sukhinina, E.A. Kudrenko, G.A. Emelchenko, Nanotechnology 22, 275718 (2011).

[8] H. Liu, C. Kuo, J. Mater. Sci. Technol. 13, 145 (1997).

[9] Munasir, Triwikantoro, M. Zainuri, Darminto, Mater. Sci. Poland 33, 47 (2015).

[10] Th. Demuth, Y. Jeanvoine, J. Hafner, J.G. Ángyan, J. Phys. Condens. Matter 11, 3833 (1999).

[11] B. Mihailova, M. Gospodinov, L. Konstantinov, J. Phys. Chem. Solids 60, 1821 (1999). 